\title{
Flow Boiling Pressure Drop Characteristics in a Rectangular Metallic Microchannel
}

\author{
Mehmed R. Özdemir'1 ${ }^{1}$ Mohamed M. Mahmoud², Tassos G. Karayiannis ${ }^{3}$ \\ ${ }^{1}$ Marmara University, Engineering Faculty, Mechanical Engineering Department \\ Istanbul 34722, Turkey \\ mehmet.ozdemir@marmara.edu.tr \\ ${ }^{2}$ Zagazig University, Faculty of Engineering \\ Zagazig 44519, Egypt \\ mbasuny@zu.edu.eg \\ ${ }^{3}$ Brunel University London, Department of Mechanical and Aerospace Engineering \\ Uxbridge UB8 3PH, UK \\ tassos.karayiannis@brunel.ac.uk
}

\begin{abstract}
The research presented in this paper is a part of long research programme on flow boiling in rectangular metallic microchannels. The present experiments were conducted in three rectangular oxygen-free copper microchannels with the same hydraulic diameter $\left(D_{h}=0.56 \mathrm{~mm}\right)$ and length $(L=62 \mathrm{~mm})$ but different aspect ratios $(\beta=$ width/height $=0.5,2.56$ and 4.94$)$. The range of mass flux and heat flux was between $200-800 \mathrm{~kg} / \mathrm{m}^{2} \mathrm{~s}$ and $4-1350 \mathrm{~kW} / \mathrm{m}^{2}$ respectively with an inlet subcooling of $\sim 14 \mathrm{~K}$. The results consistently indicated that the flow boiling pressure drop increased monotonically with heat and mass flux. Also, the flow boiling pressure drop increased with increasing vapour quality. The flow boiling pressure drop was found to increase with the decreasing channel aspect ratio. The experimental flow boiling pressure drop data were compared with widely used macro and micro scale correlations. The macro-scale correlations could not predict the experimental data well, while some of micro-scale correlations predicted the experimental results reasonably well.
\end{abstract}

Keywords: Flow boiling, Pressure drop, Aspect ratio, Microchannel.

\section{Introduction}

There is a growing body of literature that presents the importance of micro heat exchanger applications in thermal management systems for high heat flux devices with small active heat transfer areas. Micro heat exchanger applications have received a considerable attention due to their high surface area per volume ratio, compactness and lower weight. These compact heat exchangers can provide higher plant efficiency using smaller volumes of working fluids. The single-phase and flow boiling pressure drop analysis is quite important in the design of micro heat exchangers for two reasons, namely: the fact that the local flow boiling heat transfer coefficient can be determined using the saturation temperature, which is a function of the local pressure and the need to calculate the total pressure drop and hence the power required to circulate the working fluid in a pumped thermal management system. This study deals with the flow boiling pressure drop characteristics of water in rectangular metallic microchannels. Recent past literature papers on this topic are reviewed below.

A significant number of researchers reported that the flow boiling pressure drop increased with increasing mass flux and heat flux [1-11]. Lee and Mudawar [1] investigated the flow boiling pressure drop characteristics in a copper rectangular parallel microchannel $\left(D_{h}=0.35 \mathrm{~mm}\right)$ using R-134a as the working fluid. They concluded that the flow boiling pressure drop increased with heat and mass flux. However, they also noted that the flow boiling pressure drop became constant or slightly decreased after a certain value of heat flux although the heat flux was increased. The authors attributed this trend to the reduction of the flow boiling frictional pressure drop component due to the formation of complete vapour region in the downstream part of the channel with the increase in heat flux. Warrier et al. [2] analysed flow boiling pressure drop in parallel rectangular aluminium microchannels $\left(D_{h}=0.75 \mathrm{~mm}\right)$ using FC-84 as the working fluid. The authors stated that the flow boiling pressure drop increased linearly with increasing heat flux in the flow boiling region. Similar to above studies, Lee and Garimella [3] examined the flow boiling pressure drop characteristics of de-ionized water in silicon parallel 
microchannels $\left(D_{h}=0.16-0.54 \mathrm{~mm}\right)$. They reported that the flow boiling pressure drop increased with increasing mass flux and heat flux.

The effect of system pressure on the flow boiling pressure drop was also studied in the literature $[5,9,12]$. Tran et al. [9] carried out sets of experiments in two microtubes $(\mathrm{D}=2.46 \mathrm{~mm}$ and $2.92 \mathrm{~mm})$ and one rectangular microchannel $\left(D_{h}=2.4 \mathrm{~mm}\right)$ using various working fluids (R-134a, R-113 and R-12). They stated that the flow boiling pressure drop increased with decreasing system pressure in all experiments. In another study, Mahmoud et al. [12] tested four microtubes with one tube with an inner diameter of $0.52 \mathrm{~mm}$ and $100 \mathrm{~mm}$ heated length and three tubes with an inner diameter of $1.1 \mathrm{~mm}$ and different heated lengths $(150,300$, and $450 \mathrm{~mm})$ using R-134a. They concluded that the flow boiling pressure drop increased with decreasing system pressure due to the reduction of the liquid vapour density ratio.

The effect of geometrical parameters such as hydraulic diameter, channel cross-sectional area and channel aspect ratio also plays an important role on the flow boiling pressure drop [4-6, 8, 13-16]. Mahmoud et al. [5] stated that the flow boiling pressure drop per unit length increased by about $300 \%$ when the tube diameter decreased from $1.1 \mathrm{~mm}$ to $0.52 \mathrm{~mm}$. They attributed this behaviour to the high velocity gradient formation in the boundary layer due to the decrease in the diameter, which increases the frictional pressure drop component. Tong et al. [8] examined the flow boiling pressure drop and tube diameter relationship in stainless steel microtubes $(\mathrm{D}=1.05-2.44 \mathrm{~mm})$. They also found that the flow boiling pressure drop increases as the tube diameter decreases. The authors attributed this trend to the fact that as the tube diameter decreases the boundary layer gets thinner and consequently leads to higher shear stress which increases pressure drop, an explanation which is similar to [5]. In addition, Shuai et al. [13] reported that the flow boiling pressure drop of water was higher for their rectangular microchannel with smaller hydraulic diameter compared to larger microchannels $\left(\mathrm{D}_{\mathrm{h}}=0.8-2.67 \mathrm{~mm}\right)$. Mirmanto [14] conducted an experimental research with three rectangular microchannel $\left(\mathrm{D}_{\mathrm{h}}=0.44-0.64 \mathrm{~mm}\right)$ using de-ionized water. The author concluded that the flow boiling pressure drop is inversely proportional with the channel hydraulic diameter.

Harirchian and Garimella [15] performed a set of experiments in parallel rectangular microchannels using FC-77 as the working fluid. They reported that the flow boiling pressure drop increases as the channel cross-sectional area decreases. This could also, of course, be due to the reduced hydraulic diameter in agreement with the above as the diameter changed from 0.707 to $0.096 \mathrm{~mm}$ as the cross-sectional area was reduced in the experiments of [15].

The channel aspect ratio effect on the flow boiling pressure drop is examined in the literature by for example $[4,6$, 15, 16]. Harirchian and Garimella [15], stated that channels having similar cross-sectional area but different aspect ratio exhibited almost similar flow boiling pressure drop values. However, Singh et al. [6] tested silicon microchannels with the same hydraulic diameter and length $\left(D_{h}=0.14 \mathrm{~mm}\right.$ and $\left.\mathrm{L}=20 \mathrm{~mm}\right)$ but different channel aspect ratio $(\beta=1.23-$ 3.75 ) and reported that the flow boiling pressure drop first decreases with an increase in aspect ratio from 1.23 to 1.56 , and then increases with a further increase in aspect ratio at constant heat and mass flux conditions. Soupremanien et al. [16] investigated the effect of the channel aspect ratio on the flow boiling pressure drop of Forane-365HX using two rectangular aluminium microchannels having the same hydraulic diameter and length $\left(D_{h}=1.4 \mathrm{~mm}, \mathrm{~L}=83 \mathrm{~mm}\right)$ but different aspect ratio $(\beta=2.32$ and 6.99). They stated that the flow boiling pressure drop is higher for the lower aspect ratio channel for the same heat and mass flux. The authors attributed this to the strong effect of bubble confinement in the direction of the width for the lower aspect ratio channel. The size of the lower aspect ratio channel was $\mathrm{W}=2.3 \mathrm{~mm}$, $\mathrm{H}=1 \mathrm{~mm}$, while that of the high aspect ratio channel was $\mathrm{W}=5.6 \mathrm{~mm}, \mathrm{H}=0.8 \mathrm{~mm}$. This explanation may be applicable only for bubbly flow and it did not explain the high pressure drop in annular flow. Markal et al. [4] carried out an experimental study with de-ionised water in six rectangular microchannels $\left(D_{h}=0.1 \mathrm{~mm}, \mathrm{~L}=48 \mathrm{~mm}, \beta=0.37-5\right)$. They reported that there is no "regular" relationship between pressure drop and the channel aspect ratio. In a recent study, Candan et al. [17] tested pressure drop characteristics of water in a single copper rectangular channel $\left(\mathrm{D}_{\mathrm{h}}=1.2\right.$ $\mathrm{mm}, \mathrm{L}=48 \mathrm{~mm}, \beta=0.25-4$ ). They reported that the lowest values of the pressure drop are observed at $\beta=0.25$ and $\beta$ $=4$ microchannels. The authors attributed this trend to the strong thermo-hydrodynamic-geometric coupling in flow boiling. They presented the variation of total pressure drop with aspect ratio for different heat fluxes and mass fluxes. Their results show that the pressure drop data exhibit parabolic trend as the aspect ratio increase from 0.25 to 4 . The minimum pressure drop values vary between 0.7 and $1.2 \mathrm{kPa}$ due to different heat and mass flux conditions.

As mentioned in the above studies, the flow boiling pressure drop in microchannels increases with increasing heat flux and mass flux and decreasing system pressure and hydraulic diameter. However, effect of other geometrical parameters such as the channel aspect ratio on the flow boiling pressure drop was only investigated in a few studies and 
results appear to be inconclusive or in need of further clarification. Therefore, this paper reports among others on the relationship between the channel aspect ratio and flow boiling pressure drop characteristics in microchannels.

\section{Experimental Setup and Methodology}

The experimental apparatus and procedure have been described in our previous study [18]. Three rectangular oxygen free copper microchannel test sections having same hydraulic diameter and heated length $\left(\mathrm{D}_{\mathrm{h}}=0.56 \mathrm{~mm}, \mathrm{~L}=62 \mathrm{~mm}\right)$ but different aspect ratios (TS1: height $0.84 \mathrm{~mm}$, width $0.42 \beta=0.5$; TS2: height $0.39 \mathrm{~mm}$, width $1.0, \beta=2.56$; TS3: height 0.34 $\mathrm{mm}$, width 1.68 and $\beta=4.94$ ) were used in the current study. A single cartridge heater provided heating of the microchannel test sections. The local axial wall temperatures were recorded at six locations using K-type thermocouples, see fig. 1. The heat loss was reduced by using a housing made of polycarbonate. The top side of the test sections was covered with a transparent polycarbonate plate to enable flow visualization. Consequently, uniform heat flux was assumed to be applied on all three sides of the microchannel test sections. The pressure drop data was obtained directly between the channel inlet and outlet with differential pressure transducer. The channel pressure drop $\left(\Delta \mathrm{P}_{\mathrm{ch}}\right)$ and the single-phase fanning friction factor $\left(f_{c h}\right)$ can be calculated using the equations below.

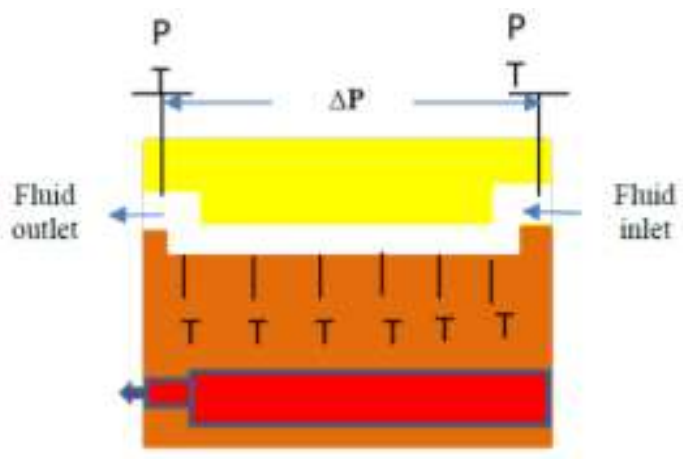

Fig. 1: Schematic representation of the test section.

$$
\begin{aligned}
f_{c h} & =\frac{\rho_{l} D_{h} \Delta P_{c h}}{2 L G^{2}} \\
\Delta P_{c h} & =\Delta P_{\text {meas }}-\Delta P_{\text {loss }}
\end{aligned}
$$

In Eq. 2, $\Delta \mathrm{P}_{\text {meas }}$ denotes the overall pressure drop measured between the channel inlet and outlet plenums. $\Delta \mathrm{P}_{\text {loss }}$ is the pressure loss due to the sudden contraction and enlargement for inlet and exit manifolds, which can be determined using Eq. 3. In Eq. 3, $V_{p}$ and $V_{c h}$ represent the liquid velocities in the plenum and channel, respectively. The flow enters and leaves the channel in a direction normal to the flow. Therefore, $\mathrm{K}_{90}$ is the loss coefficient for $90^{\circ}$ turns of the flow and is determined as 1.2, for more details see ref. [19]. $\mathrm{K}_{\mathrm{c}}$ and $\mathrm{K}_{\mathrm{e}}$ are the sudden contraction and sudden expansion loss coefficients for the channel inlet and outlet respectively. Their values were calculated based on relations given in [20].

$$
\Delta P_{\text {loss }}=2\left(\frac{1}{2} \rho_{l} V_{p}^{2} K_{90}\right)+\frac{1}{2} \rho_{l} V_{c h}^{2}\left(K_{c}+K_{e}\right)
$$

Since the fluid enters the channel as subcooled liquid, the channel can be divided into a single-phase region and flow boiling region. The single-phase region starts from the channel inlet to the location of zero thermodynamic quality with length $\mathrm{L}_{\text {sub. }}$. Then, the two phase region length $\left(\mathrm{L}_{\text {sat }}\right)$ can be defined in Eq. 4. The calculation method of $\mathrm{L}_{\text {sub }}$ requires an iterative process using Eqs. 5-7. The values of the fully developed Poiseuille number (depends on the aspect ratio), the constant $\mathrm{C}$ and the constant $\mathrm{K}(\infty)$ in Eq. 7 can be determined from [21]. The dimensionless length ( $\left.\mathrm{L}_{\text {sub }}{ }^{*}\right)$ in Eq. 7 can be evaluated by Eq. 8. The local pressure value $\left(\mathrm{P}_{\text {sat }}(\mathrm{z})\right)$ was determined using the assumption that the flow boiling pressure 
drop decreases linearly along the microchannels using Eq. 9 , where the flow boiling pressure drop $\left(\Delta \mathrm{P}_{\mathrm{tp}}\right)$ is defined in Eq. 10.

$$
\begin{aligned}
L_{s a t} & =L-L_{s u b} \\
L_{s u b} & =\frac{\dot{m} c_{p}\left(T_{s a t}-T_{i}\right)}{q "(2 H+W)} \\
P_{s a t}\left(L_{s u b}\right) & =P_{i}-\frac{2 f_{a p p} G^{2}}{\rho_{l} D_{h}} L_{s u b} \\
f_{a p p} & =\frac{3.44}{\operatorname{Re} \sqrt{L_{s u b}^{*}}}+\frac{\left(f_{F D} \operatorname{Re}\right)+\frac{K(\infty)}{4 L_{s u b}^{*}}-\frac{3.44}{\sqrt{L_{s u b}^{*}}}}{\operatorname{Re}\left(1+C\left(L_{s u b}^{*}\right)^{-2}\right)} \\
L_{s u b}^{*} & =\frac{L_{s u b}}{\operatorname{Re} D_{h}} \\
P_{s a t}(z) & =P_{s a t}\left(L_{s u b}\right)-\frac{z-L_{s u b}}{L-L_{s u b}} \Delta P_{t p} \\
\Delta P_{t p} & =\Delta P_{c h}-\Delta P_{s p}
\end{aligned}
$$

The propagated uncertainty analysis was conducted according to the method explained in [30]. The uncertainty values were $\pm 0.82-10.9 \%$ for the flow boiling pressure drop. The experimental setup was validated using single-phase experiments, see [18] for details. The correlations for developed and developing flow given by Shah [21] predicted the experimental friction factor data well for all test sections with a Mean Absolute Error (MAE) of 3.5-12.4 \%. The reproducibility of the experimental results was verified by performing and comparing pressure drop values at the same conditions at different times. The results proved to be reproducible within $\pm 0.38-7.44 \%$ which is less than the experimental uncertainty in the measured pressure drop values.

\section{Results and Discussion}

As indicated in the previous section, the working fluid enters the microchannels in a subcooled state $(\sim 14 \mathrm{~K})$. Therefore, the total channel pressure drop $\left(\Delta \mathrm{P}_{\mathrm{ch}}\right)$ consists of boiling pressure drop component $\left(\Delta \mathrm{P}_{\mathrm{tp}}\right)$ and single-phase pressure drop component $\left(\Delta \mathrm{P}_{\mathrm{sp}}\right)$. The saturated length increases as the heat flux increases. For instance, the saturated length was $0.85 \mathrm{~mm}$ (only $1.4 \%$ of the channel length) when the heat flux was $81.5 \mathrm{~kW} / \mathrm{m}^{2}$ in TS3. As the heat flux was increased to $152.6 \mathrm{~kW} / \mathrm{m}^{2}$, the saturated length became $27.63 \mathrm{~mm}$ (44.6\% of the channel length). However, the saturated region never occupies the entire channel even for the highest heat flux input $\left(56.5 \mathrm{~mm}\right.$ at $\left.1149 \mathrm{~kW} / \mathrm{m}^{2}\right)$ due to the highly subcooled input of the deionised water to the microchannels. In horizontal channels, two-phase pressure drop includes the frictional pressure drop and accelerational pressure drop components [22]. These pressure drop components can be estimated either using the homogenous flow model (HFM) or separated flow model (SFM), see [22] for the relevant equations. In the forthcoming subsections, the effect of heat flux, mass flux and channel aspect ratio on the flow boiling pressure drop is discussed.

\subsection{Effect of Heat Flux and Mass Flux on Flow Boiling Pressure Drop}

In single-phase flow, the channel pressure drop increases with mass flux at fixed heat flux and inlet temperature. Moreover, the channel pressure drop decreases as the heat input or inlet temperature increases for a given mass flux due to the variation of the thermophysical properties with temperature. On the other hand, the effect of heat flux and mass flux on the flow boiling pressure drop is slightly different. As indicated in Section 1, the flow boiling pressure drop increases with heat flux after boiling incipience at fixed mass flux conditions, $[2,4,6]$. The effects of heat flux and mass flux on the flow boiling pressure drop are presented in fig. 2 for TS $3(\beta=4.94)$ as an example. A similar trend is present for other two test 
sections. As seen in the figure, the flow boiling pressure drop increases almost linearly as the heat flux increases. This trend may be explained by the fact that the increase in heat flux increases the bubble population (active nucleation sites, higher bubble generation frequency), which increases the flow friction in microchannels. Furthermore, the vapour quality is a function of heat flux and as it increases, the frictional and accelerational pressure drop components increase. The graph also shows that the two-phase pressure drop increases with mass flux except for $\mathrm{G}=200$ and $400 \mathrm{~kg} / \mathrm{m}^{2} \mathrm{~s}$ at high heat flux values. As the mass flux increases the difference between the flow inertia and the evaporative momentum force becomes larger, which increases the accelerational pressure drop component. In addition, the frictional pressure drop component becomes larger at higher mass fluxes. The mass flux dependence can be seen in the equations of each component, where the accelerational and frictional pressure drop components increase with the term " $\mathrm{G}^{2}$ " [22]. These findings are consistent with data obtained in the literature, $[4,5,7,10,14]$.

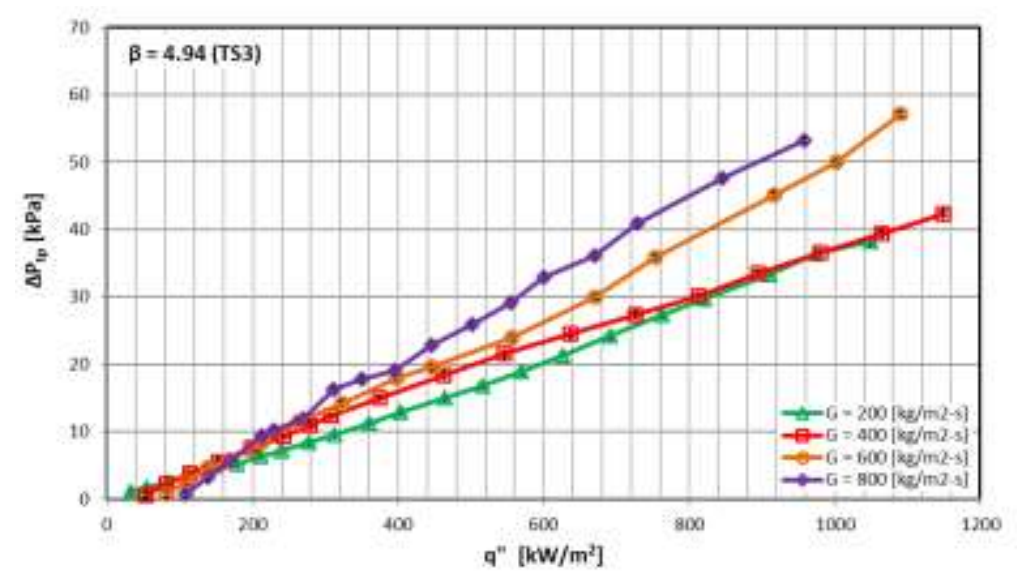

Fig. 2: Effect of heat flux and mass flux on the flow boiling pressure drop for TS3.

\subsection{Effect of Aspect Ratio on Flow Boiling Pressure Drop}

A number of past studies concluded that the pressure drop value increases as the channel diameter decreases both in single-phase and flow boiling systems $[3,5,8,14]$. This is due to the fact that the pressure drop is inversely proportional to the channel diameter. However, the effect of channel aspect ratio on flow boiling pressure drop was examined in only few studies as indicated in the Introduction section. The flow boiling pressure drop versus heat flux at the mass flux $G=600$ $\mathrm{kg} / \mathrm{m}^{2} \mathrm{~s}$ are plotted in fig. 3 for three microchannels. It can be deduced from the figure that the flow boiling pressure drop increases as the channel aspect ratio decreases. For example, at the heat flux of $600 \mathrm{~kW} / \mathrm{m}^{2}$, when the channel aspect ratio is decreased from 4.94 to 2.56 , the flow boiling pressure drop increased by about $35 \%$. Further reduction in the aspect ratio to 0.5 resulted in an increase of around $11 \%$ in flow boiling pressure drop. This is not in agreement with Singh et al. [6] who reported that the flow boiling pressure drop increases as the channel aspect ratio increases. Markal et al. [4] stated that the relationship between the total pressure drop (single-phase region + flow boiling region) and the channel aspect ratio was not clear ("regular"). Soupremanien et al. [16] found that the flow boiling pressure drop increased as the channel aspect ratio decreased; a similar finding to the present study. Two-phase pressure drop depends in complex way on the geometry of the channels (aspect ratio and absolute channel dimensions) and flow parameters (heat flux and mass flow rate) and of course prevailing flow patterns. For example, the pressure drop for TS1 and TS2 is similar but differ from TS3 for the same heat flux and mass flux. TS1 and TS2 have different aspect ratios but similar cross sectional areas $\left(0.35\right.$ and $0.39 \mathrm{~mm}^{2}$ respectively) hence the same total mass flow rate for a given mass flux $\left(600 \mathrm{~kg} / \mathrm{m}^{2} \mathrm{~s}\right.$ in figure 3$)$. The cross sectional area of TS3 is higher $\left(0.57 \mathrm{~mm}^{2}\right)$ hence the corresponding mass flow rate for a give mass flux is higher. These difference and not just the aspect ratio, could contribute to the different results depicted in figure 3 . Therefore, further work is need to elucidate the dependence of two-phase pressure drop on geometry and flow conditions. 


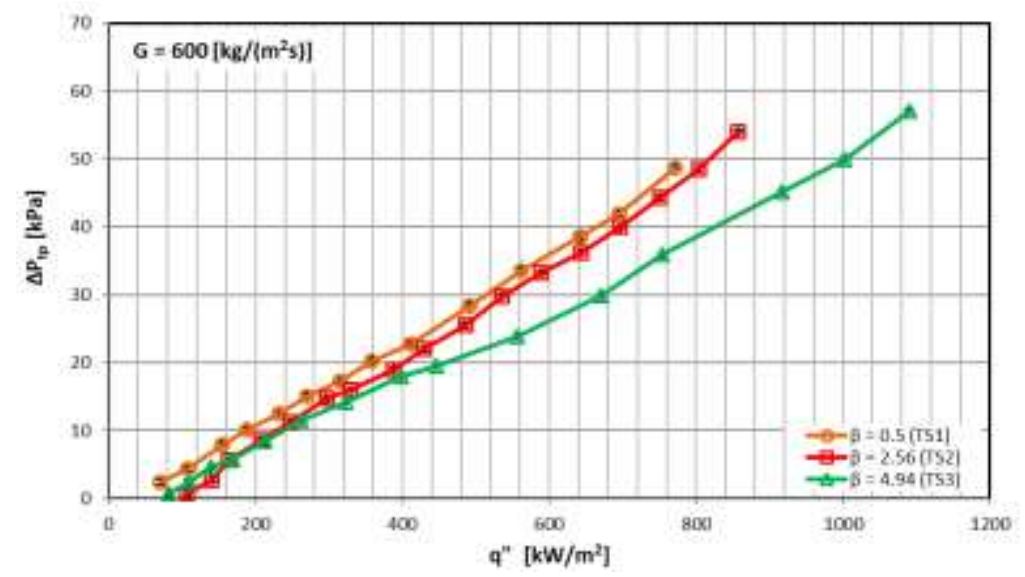

Fig. 3: Effect of aspect ratio on the flow boiling pressure drop at $\mathrm{G}=600 \mathrm{~kg} / \mathrm{m}^{2} \mathrm{~s}$.

\subsection{Comparison with Flow Boiling Pressure Drop Correlations}

Flow boiling pressure drop data were compared with ten widely used correlations for conventional [22 and 24] and micro-scale geometries. The evaluation of the correlations was conducted using the percentage of the data $(\theta)$ within \pm 30 $\%$ error bars and the Mean Absolute Error (MAE). As seen in Table 1, among the conventional scale correlations the Separated Flow Model (SFM) of [24] predicted the experimental data better than the Homogenous Flow Model (HFM) [22]. The reason of this might be attributed to the void fraction, i.e. in the SFM, the void fraction was developed mainly based on the annular flow regime which is similar to the current study. However, the HFM assumes that both phases can be modelled as one continuous phase.

The experimental flow boiling pressure drop data are compared with eight micro-scale correlations. It was found that the Mishima and Hibiki [23], Yu et al. [25] and Zhang et al. [27] correlations predict the data reasonably well.

Table 1: MAE and the percentage of data within error bands for flow boiling pressure drop correlations.

\begin{tabular}{|l|l|l|l|l|l|l|}
\hline \multirow{2}{*}{ Correlation } & \multicolumn{2}{|l|}{$\beta=0.5(\mathrm{TS} 1)$} & \multicolumn{2}{c|}{$\beta=2.56(\mathrm{TS})$} & \multicolumn{2}{l|}{$\beta=4.94(\mathrm{TS} 3)$} \\
\cline { 2 - 7 } & MAE \% & $\theta \%$ & MAE \% & $\theta \%$ & MAE \% & $\theta \%$ \\
\hline Lockhart and Martinelli [24] & 44 & 50 & 30.6 & 50 & 39.4 & 47.2 \\
\hline Homogenous model [22] & 242.7 & 7.45 & 170 & 1.9 & 176.6 & 6.4 \\
\hline Mishima and Hibiki [23] & 25.9 & 56.3 & 35.1 & 32.4 & 26.8 & 55.6 \\
\hline Yu et al. [25] & 29 & 59.4 & 38 & 32.8 & 31.9 & 47.2 \\
\hline Warrier et al. [2] & 214.7 & 6.3 & 183.2 & 8.3 & 226.1 & 5.2 \\
\hline Qu and Mudawar [26] & 49.2 & 26.6 & 12.4 & 75 & 50.1 & 35.3 \\
\hline Lee and Garimella [3] & 121.5 & 9.4 & 70.6 & 16.1 & 110.7 & 13.1 \\
\hline Zhang et al. [27] & 19.5 & 70.3 & 20 & 68.8 & 23.4 & 68.1 \\
\hline Li and Wu [28] & 48.6 & 37.5 & 50.9 & 45.8 & 59.8 & 23.6 \\
\hline Lee et al. [29] & 98.5 & 26.6 & 47.6 & 34.3 & 79 & 28.4 \\
\hline
\end{tabular}

\section{Conclusion}

The flow boiling pressure drop results were presented and discussed for three microchannels having the same hydraulic diameter $(0.56 \mathrm{~mm})$ and length $(62 \mathrm{~mm})$ and different aspect ratios $(0.5,2.56$, and 4.94$)$. The results showed that the flow boiling pressure drop increased almost linearly with heat flux and mass flux for all test sections. Increasing heat flux enhances the bubble generation rate during flow boiling, which in turn increases the flow resistance in the microchannels. As the mass flux increases the accelerational pressure drop component increases due to increase in the difference between the inertia force and the evaporation momentum force. The frictional pressure drop component also becomes higher at high mass fluxes. The channel aspect ratio effect on the flow boiling pressure drop was also examined. This has a complex dependence on the absolute channel dimensions, aspect ratio, flow parameters and prevailing flow regimes. The 
experimental flow boiling pressure drop data were compared with two macro-scale correlations and eight micro-scale correlations available in the literature. The Lockhart-Martinelli [24] SFM correlation predicted the experimental data better than than the HFM [22]. The micro-scale correlations proposed by Mishima and Hibiki [23], Yu et al. [25] and Zhang et al. [27] predicted reasonably the experimental flow boiling pressure drop results with the Zhang et al. [27] correlation performing slightly better.

\section{Nomenclature}

\begin{tabular}{|c|c|c|c|}
\hline$C_{p}$ & Specific heat $[\mathrm{J} / \mathrm{kg} \mathrm{K}]$ & $L_{\text {sat }}$ & Two phase length, [m] \\
\hline C & Correction factor, [-] & $L_{s u b}^{*}$ & Dimensionless length, [-] \\
\hline$D_{h}$ & Hydraulic diameter, [m] & $\dot{m}$ & Mass flow rate, $[\mathrm{kg} / \mathrm{s}]$ \\
\hline$f_{c h}$ & Single-phase fanning friction factor, [-] & $P_{i}$ & Inlet Pressure, $[\mathrm{Pa}]$ \\
\hline$f_{\text {app }}$ & Apparent friction factor, $[-]$ & $P_{\text {sat }}$ & Saturation pressure, $[\mathrm{Pa}]$ \\
\hline$f_{F D}$ & Fully developed friction factor, [-] & $q^{\prime \prime}$ & Heat flux, $\left[\mathrm{W} / \mathrm{m}^{2}\right]$ \\
\hline G & Mass flux, $\left[\mathrm{kg} / \mathrm{m}^{2} \mathrm{~s}\right]$ & $R e$ & Reynolds number, [-] \\
\hline$H$ & Channel height, $[\mathrm{m}]$ & $T_{i}$ & Inlet temperature, $[\mathrm{K}]$ \\
\hline$K_{90}$ & $90^{\circ}$ turn loss coefficient, [-] & $T_{\text {sat }}$ & Saturation temperature, $[\mathrm{K}]$ \\
\hline$K_{e}$ & Expansion loss coefficient, [-] & $V_{c h}$ & Channel fluid velocity, $[\mathrm{m} / \mathrm{s}]$ \\
\hline$K_{c}$ & Contraction loss coefficient, [-] & $V_{p}$ & Plenum fluid velocity, [m/s] \\
\hline$K(\infty)$ & Pressure drop number, [-] & $W$ & Channel width, $[\mathrm{m}]$ \\
\hline$L$ & Length, $[\mathrm{m}]$ & $z$ & Axial distance, $[\mathrm{m}]$ \\
\hline$L_{s u b}$ & Single phase length, $[\mathrm{m}]$ & & \\
\hline \multicolumn{4}{|c|}{ Greek symbols } \\
\hline$\theta$ & $\begin{array}{l}\text { Percentage of data within } \pm 30 \% \text { error, } \\
{[-]}\end{array}$ & $\Delta P_{\text {meas }}$ & Measured pressure drop, $[\mathrm{Pa}]$ \\
\hline$\beta$ & Aspect ratio, W/H, [-] & $\Delta P_{\text {loss }}$ & Pressure losses, $[\mathrm{Pa}]$ \\
\hline$\Delta P_{c h}$ & Channel pressure drop, $[\mathrm{Pa}]$ & $\Delta P_{s p}$ & Single phase pressure drop, $[\mathrm{Pa}]$ \\
\hline$\Delta P_{t p}$ & Two phase pressure drop, $[\mathrm{Pa}]$ & $\rho_{l}$ & Liquid density, $\left[\mathrm{kg} / \mathrm{m}^{3}\right]$ \\
\hline
\end{tabular}

\section{References}

[1] J. Lee and I. Mudawar, "Two-phase flow in high-heat-flux micro-channel heat sink for refrigeration cooling applications: Part I - pressure drop characteristics," Int. J. of Heat and Mass Transfer, vol. 48, no. 5, pp. 928 - 940 , 2005.

[2] G. R. Warrier, V. K. Dhir and L. A. Mamoda, "Heat transfer and pressure drop in narrow rectangular channels," Experimental Thermal and Fluid Science, vol. 26, no. 1, pp. 53 - 64, 2002.

[3] P. S. Lee and S. V. Garimella, "Saturated flow boiling heat transfer and pressure drop in silicon microchannel arrays," Int. J. of Heat and Mass Transfer, vol. 51, no. 3, pp. 789 - 806, 2008.

[4] B. Markal, O. Aydin and M. Avc1, "Effect of aspect ratio on saturated flow boiling in microchannels," Int. J. of Heat and Mass Transfer, vol. 93, pp. 130 - 143, 2016.

[5] M. M. Mahmoud, T. G. Karayiannis and D. B. R. Kenning, "Flow boiling in small to microdiameter tubes," Encyclopedia of Two Phase Heat Transfer and Flow IV, vol. 3, chapter 4.

[6] S. G. Singh, A. Kulkarni, S. P. Duttagupta, B. P. Puranik and A. Agrwal, "Impact of aspect ratio on flow boiling of water in rectangular microchannels," Experimental and Thermal Fluid Science, vol. 33, no. 1, pp. 153 - 160, 2008.

[7] E. Sobierska, R. Kulenovic, R. Mertz and M. Groll, "Experimental results of flow boiling of water in a vertical microchannel," Experimental Thermal and Fluid Science, vol. 31, no. 2, pp. 111 - 119, 2006.

[8] W. Tong, A. E. Bergles and M. K. Jensen, "Pressure drop with highly subcooled flow boiling in small - diameter tubes," Experimental Thermal and Fluid Science, vol. 15, no. 3, pp. $202-212,1997$.

[9] T. N. Tran, M. C. Chyu, M. W. Wamsganss and D. M. France, "Two - phase pressure drop of refrigerants during flow boiling in small channels: an experimental investigation and correlation development," Int. J. of Multiphase Flow, vol. 26, no. 11, pp. 1739 - 1754, 2000.

[10] R. Yun, J. H. Heo and Y. Kim, "Evaporative heat transfer and pressure drop of R410A in microchannels," Int. J. of refrigeration, vol. 29, no. 1, pp. 92 - 100, 2006. 
[11] L-m. Pan, R-g. Yan, H-j. Huang, H. He and P-f. Li, "Experimental study on the flow boiling pressure drop characteristics in parallel multiple microchannels," Int. J. of Heat and Mass Transfer, vol. 116, pp. 642 - 654, 2018.

[12] M. M. Mahmoud, T. G. Karayiannis and D. B. R. Kenning, "Flow Boiling Pressure Drop of R134a in Microdiameter Tubes: Experimental Results and Assesment of Correlations," Heat Transfer Engineering, vol. 35, no. 2, pp. 178-192, 2014.

[13] J. Shuai, R. Kulenovic and M. Groll, "Heat transfer and pressure drop for flow boiling of water in narrow vertical rectangular channels," in Proceedings of the first International Conference on Microchannels and Minichannels, Rochester, NY, 2003, pp. $667-673$.

[14] M. Mirmanto, "Local pressure measurements and heat transfer coefficient of flow boiling in a rectangular microchannel," Heat and Mass Transfer, vol. 52, no. 1, pp. 73 - 83, 2016.

[15] T. Harirchian and S. V. Garimella, "The critical role of channel cross - sectional area in microchannel flow boiling heat transfer," Int. J. of Multiphase Flow, vol. 35, no. 10, pp. 904 - 913, 2009.

[16] U. Soupremanian, S. Le Person, M. Favre - Marinet and Y. Bultel, "Influence of the aspect ratio on boiling flows in rectangular mini - channels," Experimental thermal and fluid science, vol. 35, no. 5, pp. 797 - 809, 2011.

[17] A. Candan, B. Markal, O. Aydın and M. Avc1, "Saturated flow boiling characteristics in single rectangular minichannels: effect of aspect ratio," Exp. Heat Transfer, vol. 31, no. 6, pp. 531 - 551, 2018.

[18] M. R. Özdemir, M. M. Mahmoud and T. G. Karayiannis, "Flow boiling heat transfer in a rectangular copper microchannel," J. of Thermal Engineering, vol. 2, no. 2, pp. 761 - 773, 2016.

[19] S. Kandlikar, S. Garimella, D. Li, S. Colin and M. R. King, "Heat Transfer and Fluid Flow in minichannels and microchannels," Elsevier, 2005.

[20] R. K. Shah and A. R. London, "Laminar Flow Forced Convection in Ducts", in Advances in Heat Transfer, Oxford: Academic Press, 1978.

[21] R. K. Shah, "A correlation for laminar hydrodynamics entry length solution for circular and noncircular ducts," J. of Fluids Engineering, vol. 100, pp. 177 - 179, 1978.

[22] J. G. Collier and J. R. Thome, Convective Boiling and Condensation. Oxford: Oxford University Press, 2009.

[23] K. Mishima and T. Hibiki, "Some characteristics of air-water two-phase flow in small diameter vertical tubes," Int. J. of Multiphase Flow, vol. 22, no. 4, pp. 703 - 712, 1996.

[24] R.W. Lockhart and R. C. Martinelli, "Proposed correlation of data for isothermal two-phase two-component flow in pipes," Chemical Eng. Progress, pp. 45 - 39, 1949.

[25] W. Yu, D. M. France, M. W. Wambsganss and J. R. Hull, "Two-phase pressure drop, boiling heat transfer and critical heat flux to water in small-diameter horizontal tube," Int. J. of Multiphase Flow, vol. 28, pp. 927 - 941, 2002.

[26] W. Qu and I. Mudawar, "Measurement and prediction of pressure drop in two-phase microchannel heat sinks," Int. J. of Heat and Mass Transfer, vol. 46, no. 15, pp. 2737 - 2753, 2003.

[27] W. Zhang, T. Hibiki and K. Mishima, "Correlation of two-phase pressure drop and void fraction in mini-channel," Int. J. of Heat and Mass Transfer, vol. 53, pp. 453-465, 2010.

[28] W. Li and Z. Wu, "A general correlation for adiabatic two - phase pressure drop in micro/mini-channels," Int. J. of Heat and Mass Transfer, vol. 53, pp. 2732 - 2739, 2010.

[29] H. J. Lee, D. Y. Liu, Y. Alyousef and S-C. Yao, "Generalized two-phase pressure drop and heat transfer correlations in evaporative micro/mini channels," J. of Heat Transfer, vol. 132, pp. 041004-1 - 041004-9, 2010.

[30] H. W. Coleman and W. G. Steele, Experimentation, validation and uncertainty analysis for engineers. New Jersey, USA: John Wiley and Sons, 2009. 